\title{
Using Doppler lidar systems to detect atmospheric turbulence in Iceland
}

\author{
Shu Yang ${ }^{1,2}$, Guðrún Nína Petersen², Sibylle von Löwis² ${ }^{2}$ Jana Preißler $^{3}$, David Christian \\ Finger $^{1}$ \\ 1) Reykjavik University, School of Science and Engineering, Reykjavik, Iceland \\ 2) Icelandic Meteorological Office, Reykjavik, Iceland \\ 3) Centre for Climate and Air Pollution Studies, National University of Ireland, Galway, \\ University Road, H91CF50, Galway, Ireland
}

\begin{abstract}
The temporal and spatial scale of atmospheric turbulence is very dynamic, requiring an adequate method to detect and monitor turbulence with high resolution. Doppler Light Detection and Ranging (lidar) systems have been used widely to observe and monitor wind velocity and atmospheric turbulence profiles. Lidar systems can provide continuous information about wind fields using the Doppler effect from emitted light signals. In this study, we use a Leosphere Windcube 200S lidar system stationed in Reykjavik, Iceland, to evaluate turbulence intensity by estimating eddy dissipation rate (EDR). For this purpose, we retrieved radial wind velocity observations from velocity azimuth display (VAD) scans to compute EDR based on the Kolmogorov theory. We compared different noise filter methods, scan strategies and calculation approaches during different selected weather conditions to assess the accuracy of our EDR estimations. The results reveal that the lidar observations can detect and quantify atmospheric turbulence with high spatial and temporal resolution, our algorithm can retrieve EDR and indicate the turbulence intensity. These results suggest that lidar observation can be of high importance for potential end-user, e.g. air traffic controllers at the local airport. The work is an important step towards enhanced aviation safety in a subpolar climate characterized by severe wind turbulence.
\end{abstract}

\section{Introduction}

Extreme weather phenomena can have hazardous impacts on aviation safety (Sharman, 2016). In particular, turbulent headwinds during aircraft take-off or landing can lead to critical situations. The headwind is the relative air motion in an opposite sense to the direction of the aircraft, provides the lift of an aircraft(Hon and Chan, 2014). According to the safety report of the International Civil Aviation Authorities (ICAO), more than one-third of aircraft accidents 
1 in 2017 occurred during take-off and landing (ICAO, 2018). During take-off and landing

2 phases, rapid and large changes in headwind can be a severe threat to aircraft safety. In such situations, the air speed is relatively low and proximity to the surface leaves little room for taking corrective measures (Hon and Chan, 2014). turbulence. Detection of turbulence is a common issue in the aviation sector, here we focus on the detection in Iceland.

Iceland, located in the North Atlantic Ocean, is well known for particular turbulent weather situations, leading frequently to aviation safety concerns. Strong winds and large wind speed variations are frequent in Iceland (Ólafsson and Ágústsson, 2007), and detecting turbulence to enhance aviation safety is notably relevant in Iceland.

By definition, the scale of atmospheric turbulence varies from the macroscale to microscale. The eddies that affect aviation the most have a spatial scale between about $100 \mathrm{~m}$ and $1 \mathrm{~km}$ (Sharman, 2016). It is hard to detect and monitor turbulence continuously with conventional instruments, such as meteorological masts, which only measure the wind at some certain altitude; or weather balloon, which only measures at some certain time. In order to detect and quantify turbulence and get a clearer picture of the wind conditions, several international airports, e.g. Hong Kong (Chan, 2010), Sendai (Misaka et al., 2008), have installed light detection and ranging (lidar) systems.

The use of lidars for remote sensing of wind has been increasing in the last decade. In addition to being used in the aviation sector (Hon and Chan, 2014; Leung et al., 2018), they are widely used in the wind energy sector (Wächter and Rettenmeier, 2009) as well as in meteorology research (Manninen et al., 2018; Tuononen et al., 2017). Compared to the use of conventional methods like anemometers and radio sounding, lidars have the advantage of continuous measurement at high temporal and spatial resolution. Accordingly, lidar systems allow the monitoring of wind fields within and above the boundary layer without the need of masts, which is especially important for mobile installation. Also, tall masts may not be desirable in some places, e.g. at airports. The lidars can also be mobile and can therefore easily be deployed at different locations, allowing for flexibility for measurements during e.g. an event or campaign.

There is existing research on turbulence detection using Doppler lidar, from theoretical approach to practical research: (Frehlich, 2001; Frehlich et al., 2006; Frehlich and Cornman, 2002) developed a method to estimate turbulence intensity from Kolmogorov theory; In Europe, some studies have been done on retrieving turbulence intensity from lidar datasets (e.g. (O’Connor et al., 2010; Thobois et al., 2015)); At Hong Kong International Airport, lidars have been applied to detect low-level turbulence (Chan, 2009; Hon and Chan, 2014; Leung et al., 2018). However, the use of lidars for turbulence intensity detection in high latitude regions, such as Iceland, has received little attention. An algorithm to retrieve turbulence intensity from the vertical lidar scans, hereafter called vertical stares as the beam is kept in vertical position, has been developed in Finland (O'Connor et al., 2010). Horizontal wind velocity is generally an order of magnitude larger than vertical velocity, and aircrafts with high air speed and wind loading are sensitive to head/tail wind variations (Sinclair and Kuhn, 1991). Accordingly, it is valuable and meaningful to develop an algorithm to retrieve the turbulence intensity from the lidar dataset of horizontal wind velocity in Iceland.

46 In this study, we derive turbulence intensity by computing the eddy dissipation rate (EDR) 47 from wind profile data, acquired using a Leosphere Windcube 200S Doppler lidar system 
Atmos. Meas. Tech. Discuss., https://doi.org/10.5194/amt-2019-3

1 (Leosphere, Inc, 2013) located at the Icelandic Meteorological Office (IMO) in Reykjavik, 2 Iceland. The results are compared to vertical stares using O'Connor et al. (2010)'s method. 3 And we also compared two calculation approaches and different data filtering methods. The 4 next section contains information about the lidar system and the dataset. The algorithm to 5 retrieve turbulence intensity from lidar dataset is described as well. The results are presented 6 in Sect. 3 and final conclusion and discussions in the last section.

\section{Methodology}

\section{$8 \quad 2.1$ Instruments}

9 Two identical lidar systems are currently in operation in Iceland, Leosphere Windcube 200S

10 Doppler scanning lidars with a depolarization module. That module can distinguish the shape of particles in the atmosphere, but will not be applied in this study. One is located at Keflavik International Airport and the other system is a mobile one installed on a trailer. The mobile system is currently located at IMO's headquarters in Reykjavik. Here we use data from the latter system.

Table 1. The specifications of the lidars operated in Iceland (Leosphere, Inc, 2013).

\begin{tabular}{|l|l|}
\hline & Specification \\
\hline Company & LEOSPHERE GROUP \\
\hline Modite: & http://www.leosphere.com \\
\hline Wavelength & Windcube 200S \\
\hline Maximum Power & $1.54 \mu \mathrm{m}$ \\
\hline Pulse Width & $5 \mathrm{~mW}$ \\
\hline Range resolution & $200 \mathrm{~ns}$ \\
\hline Maximum detection range & $12 \mathrm{~km}$ \\
\hline Azimuthal angle range & $0-360^{\circ}$ \\
\hline Elevation angle range & $-10-190^{\circ}$ \\
\hline
\end{tabular}

16 A Doppler lidar can measure radial wind speed along the beam based on the Doppler effect. 17 From radial wind speed and direction, we can retrieve profiles of wind velocity, wind direction, 18 and turbulence intensity, as explained in detail in Sect. 2.3.

\section{$19 \quad 2.2$ Scanning settings}

20 The lidar systems can be programmed to scan the surrounding atmosphere. The scan strategy used in this work is described as follows: 
- Every 15 minutes there were $360^{\circ}$ revolution velocity-azimuth-display (VAD) scans at elevation angles of $15^{\circ}$ and $75^{\circ}$

- Between VAD scans, vertical stares, at $90^{\circ}$ elevation angle, were performed continually

- Every day, early in the morning, a hard target scan was performed at a low elevation angle checking pointing accuracy of the lidar

The lidar measures the radial velocity, or Doppler velocity, along the line of sight (LOS), and both vertical stare and VAD scans can acquire information on turbulence intensity. In the first step, we will focus on VAD scans and an approach which has been used extensively in the literature and operation (Frehlich et al., 2006; Hon and Chan, 2014; Thobois et al., 2015). The horizontal wind components, which is of importance for aviation safety, can be retrieved from VAD scans. Data from vertical stares will be used as verification reference in this study.

\section{$12 \quad 2.3$ Theory on Turbulence estimation}

The turbulent eddy dissipation rate (EDR, $\varepsilon$ ) can be used as a turbulence intensity indicator as it represents the conversion of turbulent kinetic energy to heat(Cohn, 1994; Hocking, 1985). There are several approaches to retrieve EDR value from lidar observations. (Frehlich and Cornman, 2002) estimated EDR and the length scale from velocity data. (Oude Nijhuis et al., 2018) compared different methods to retrieve EDR from wind velocity, from Doppler radar though. (Thobois et al., 2015) explored the possibility to estimate EDR by using a Leosphere Windcube lidar in Toulouse, France. In this study, we developed an algorithm to estimate EDR by using the velocity structure function, and applied the algorithm on our lidar in Reykjavik. This method is based on the Kolmogorov theory (Frehlich, 2001), assuming the atmosphere is isotropic and homogeneous over the observation domain.

The radial velocity $V_{r}$, as measured by the Doppler lidar, can be given by:

$$
V_{r}=U \sin \varphi \cos \theta+V \cos \varphi \cos \theta+W \sin \theta \quad \text { (Eq. 2.1) }
$$

Where $U, V$ and $W$ are the wind components in $\mathrm{x}, \mathrm{y}$ and $\mathrm{z}$ direction, $\varphi$ is the azimuthal angle, where $0^{\circ}$ points to the north, and $\theta$ the elevation angle, where $90^{\circ}$ points vertically (Fig. 1). 
Atmos. Meas. Tech. Discuss., https://doi.org/10.5194/amt-2019-3

Manuscript under review for journal Atmos. Meas. Tech.

Discussion started: 9 January 2019

(c) Author(s) 2019. CC BY 4.0 License.

1

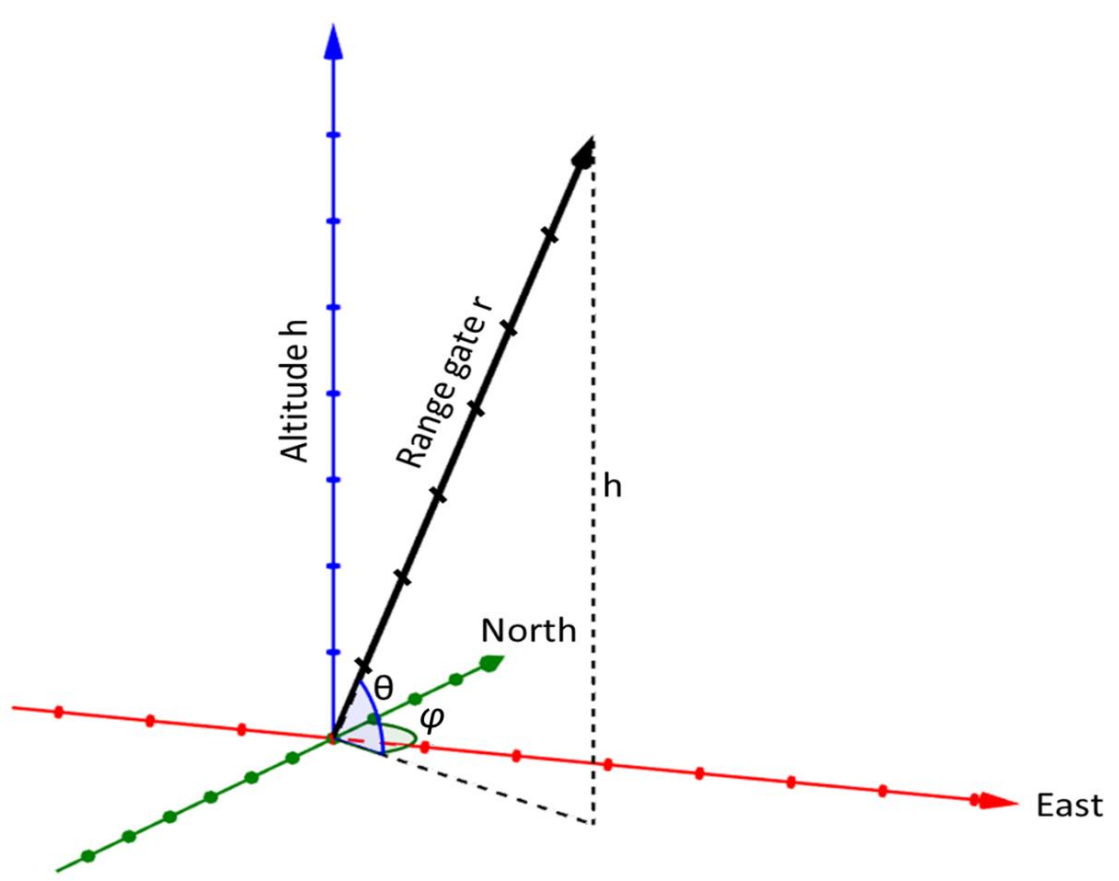

Figure 1. A schematic of the lidar beam vector (black). The azimuth angle, $\varphi$, is shown in green with north being $0^{\circ}$ and the elevation angle, $\theta$, in blue with $90^{\circ}$ representing a vertical beam. $h$ is the altitude of the range gate, and $r$ is the measurement distance along the beam.

If the atmosphere is homogeneous and isotropic, the Kolmogorov theory can be applied and the energy spectrum will fit the $-5 / 3$ slope (Fig. 2) as follows:

$$
E(k)=C \varepsilon^{2 / 3} k^{-5 / 3} \quad(\text { Eq. 2.2) }
$$

where $C$ is Kolmogorov constant, $\varepsilon$ is the energy dissipation rate, $k$ is the wavenumber.

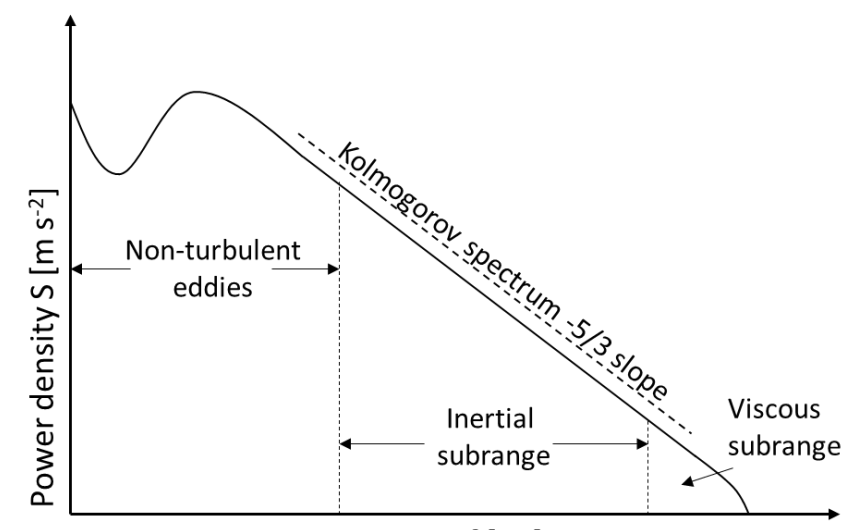

Frequency $\mathrm{f}[\mathrm{Hz}]$ 
Atmos. Meas. Tech. Discuss., https://doi.org/10.5194/amt-2019-3

1 Figure 2. A schematic of the wind velocity power density as a function of frequency

2 conforming to Kolmogorov's hypothesis (redrawn from (O'Connor et al., 2010; Thobois et al., 3 2015)).

4 If the atmosphere is isotropic and the liner relationship between the power density and the

5 frequency is close to $-5 / 3$ (Figure 2), a direct relationship between the energy spectrum $E(K)$

6 and the structure function $D_{v}$ can be defined (Frehlich et al., 2006; Thobois et al., 2015). For a

7 scanning lidar, the EDR $\left(\varepsilon\right.$, in unit $\left.m^{2} s^{-3}\right)$ can be obtained by fitting the $-5 / 3$ slope for the

8 structure function; then we have

$$
D_{v}=C_{v} \varepsilon^{2 / 3} s^{2 / 3}
$$

where $C_{v} \sim 2$ is the Kolmogorov constant.

The velocity structure function $D_{v}$ is given by:

$$
D_{v}=<\left(v^{\prime}(r)-v^{\prime}(r+s)\right)^{2}>
$$

where

are the fluctuations from the mean velocity $\langle\mathrm{v}(\mathrm{r})\rangle$ at a certain range gate $\mathrm{r}$ (Frehlich et al., 2006) and $s$ is the spatial difference. The distance to range gate $r$ can easily be converted to height $\mathrm{h}$ by using trigonometric functions:

$$
h=r \sin \theta
$$

(Eq. 2.6)

The structure function can be estimated either along a transverse direction (one azimuth angle to another), which is the azimuthal approach, or along the lidar beam direction (one range gate to another), which is the longitudinal approach. Accordingly, $s$ will vary based on this approach. The comparison between the two approaches will be presented in Sect. 3.2.

Besides the VAD scans, data from the vertical stares were used in this study. (O'Connor et al., 2010) developed a method to estimate EDR, based on the velocity variance from vertical stares. This method will be applied in our case and is used as validation reference. 
Atmos. Meas. Tech. Discuss., https://doi.org/10.5194/amt-2019-3

Manuscript under review for journal Atmos. Meas. Tech.

Discussion started: 9 January 2019

(c) Author(s) 2019. CC BY 4.0 License.

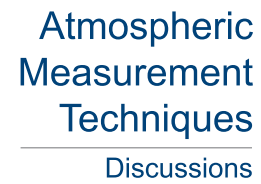

(c) (1)

Discussions

13 Results

\subsection{Noise filtering}

3

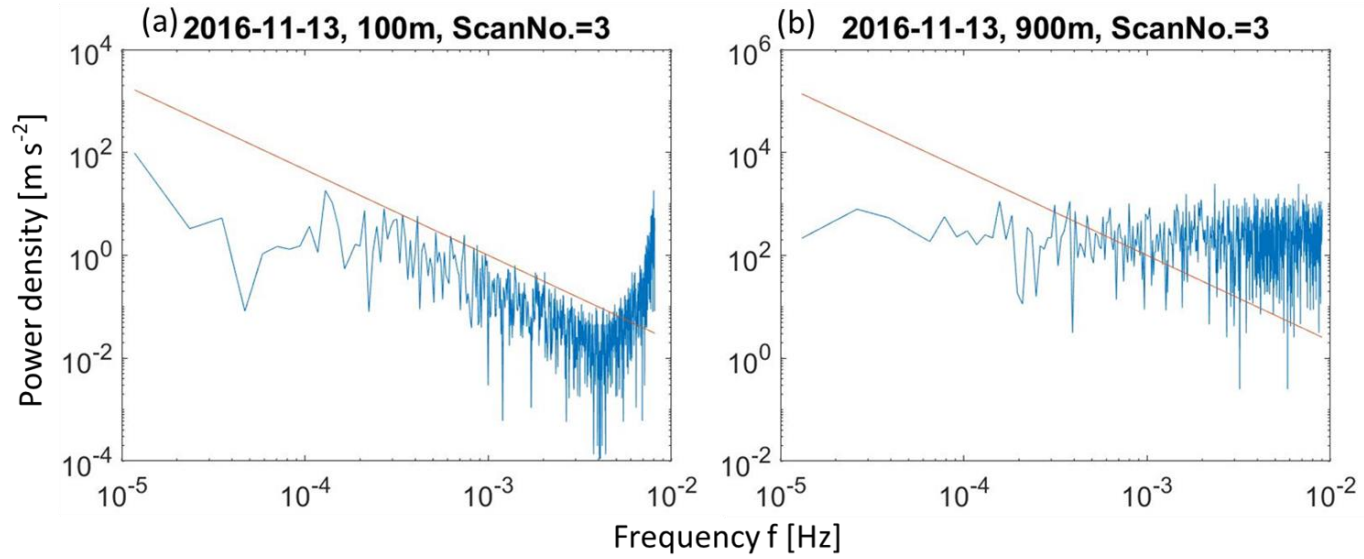

4

Figure 3. Verification of data quality: the velocity energy spectrum (blue curve, derived from vertical velocity profile) should correspond to a $-5 / 3$ slope (red line). A good case (a) versus a bad case (b) from the same day (13 November 2016) data with different altitude (100 $\mathrm{m}$ for (a) and $900 \mathrm{~m}$ for (b)).

First, we investigate observed velocity energy spectra, derived from vertical stare data using Fast Fourier Transform (FFT) method, to confirm that it agrees with the expected $-5 / 3$ slope. The results vary from one profile to another, but in general, the energy spectrum fits the idealized slope better at lower altitude. Figure 3 shows two examples of one hour vertical stare data on 13 November 2016, at different altitudes (100 m and $900 \mathrm{~m}$ ). The bias between the signal (blue) and the theoretical slope (red) is likely a result of signal noise at different heights. The lidar signal is backscattered by fine particles in the atmosphere, thus signal quality is better at lower altitude, where there are more particles, than higher altitude (Ramanathan et al., 2001). In high latitude regions like Iceland, the mixing layer is shallower than at intensively studied continental mid-latitude sites, and the number of scatters is relatively smaller. This could amplify this bias as well.

(Manninen et al., 2016) estimated the uncertainty introduced by noise when they quantified turbulence intensity via lidar data and they developed a background correction algorithm to increase data availability. We have applied this algorithm on the lidar data from vertical stare, but it is not implemented for VAD scans yet. To distinguish valid data from unrealistic data points, or noise, we applied a filter based on the carrier-to-noise ratio (CNR) and lidar confidence index (CI). CNR indicates the quality of the data received. Higher CNR means a better received signal. Confidence index (0 to 100) is a built-in variable provided by the lidar manufacturer for quality control. There are two ways to apply the filters: before EDR calculation or after EDR calculation. The different filtering methods are named as shown in Table 2.

Table 2. Filter methods tested in this study. 
Atmos. Meas. Tech. Discuss., https://doi.org/10.5194/amt-2019-3

Atmospheric

Manuscript under review for journal Atmos. Meas. Tech.

Discussion started: 9 January 2019

(c) Author(s) 2019. CC BY 4.0 License.

\begin{tabular}{|l|c|c|}
\hline & Before-calculation filter & After-calculation filter \\
\hline CI only & CI-B & CI-A \\
\hline CNR only & CNR-B & CNR-A \\
\hline CNR and CI & Combi-B & Combi-A \\
\hline
\end{tabular}

Applying the filter before calculation may remove most of the noise, but also some realistic observations, while after calculation the filter may keep some unexpected noise, especially with the longitudinal approach. Figure 4 shows the effect of different filters. Figure 4(a) and 4(b) show CNR and CI on 24 March 2017. The calculated EDR (longitudinal approach) without any filter is shown in Fig. 4(c). Figure 4(d), 4(e), and 4(f) are filtered results of 4(c), with Combi-A, CI-B, and Combi-B filters, respectively. The thresholds for CNR and confidence index filter are $-32 \mathrm{~dB}$ and 99 in this case. The CNR profile of the lidar data can vary greatly, which makes it risky to have a constant threshold: a high threshold may remove too many data points while a low threshold may keep too much noise. The optimal CNR threshold was, based on numerous tests, identified to be $-32 \mathrm{~dB}$ at which the data availability is maximized and the same time the noise minimized. Before-calculation filters are more sensitive to this threshold, compared to after-calculation filters.
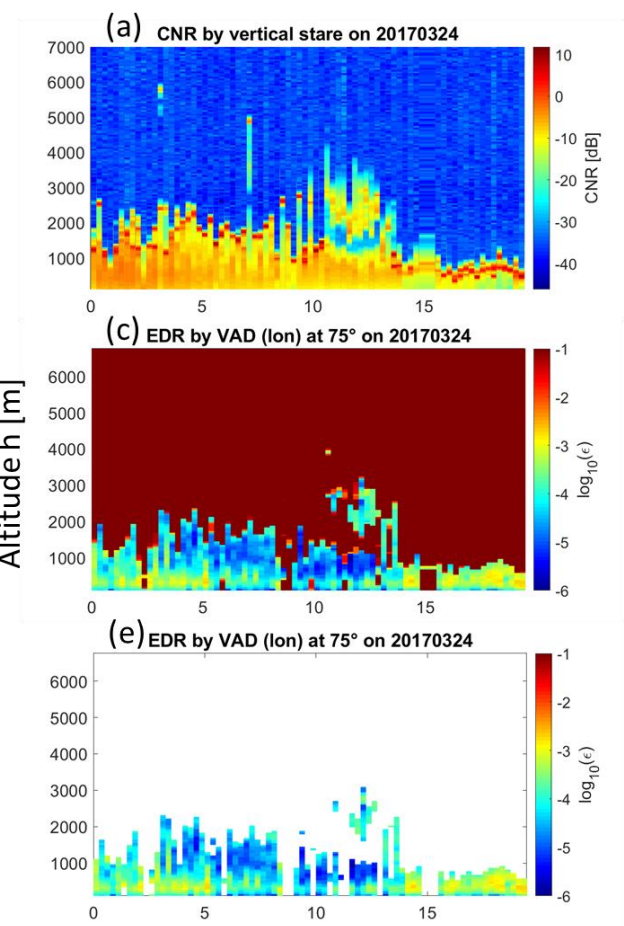

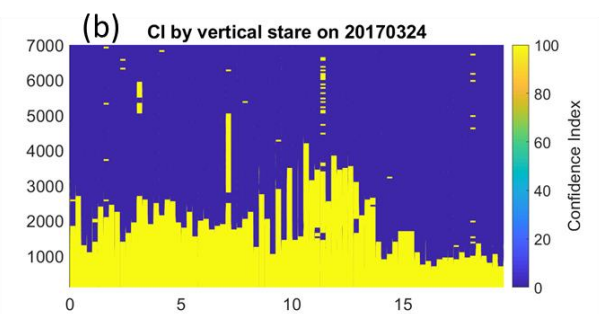

(d) EDR by VAD at $75^{\circ}$, RVK on 20170324

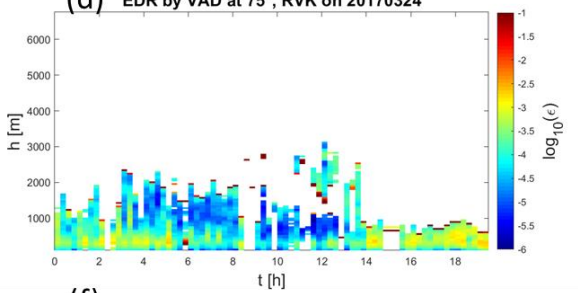

(f) EDR by VAD (lon) at $75^{\circ}$ on 20170324

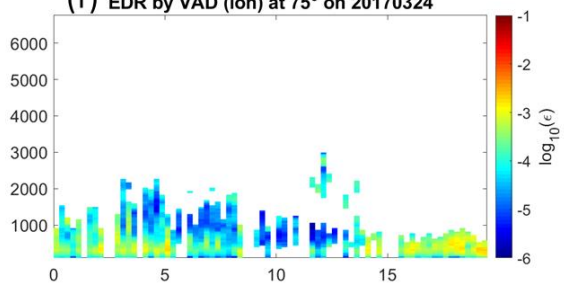

13

Figure 4. The carrier-to-noise ratio $(C N R)$ in $d B(a)$, the Confidence Index $(C I)(b)$, the base 10 logarithm of EDR $\left[\mathrm{m}^{2} \mathrm{~s}^{-3}\right]$ without filter $(c)$, with Combi-A filter $(d), C I-B$ filter $(e)$ and 
Atmos. Meas. Tech. Discuss., https://doi.org/10.5194/amt-2019-3

Manuscript under review for journal Atmos. Meas. Tech.

Discussion started: 9 January 2019

(c) Author(s) 2019. CC BY 4.0 License.

\section{Atmospheric \\ Measurement \\ Techniques}

Discussions

1 Combi-B filter $(f)$ on 24 March 2017. The EDR is derived from VAD scans, with $75^{\circ}$ elevation

2 angle and using longitudinal approach.

3 The impact of different filters is stronger for single VAD scans. Figure 5 compares EDR

4 along each beam by filtering after calculation (Combi-A, left panel) and filtering before

5 calculation (Combi-B, right panel) and gives three examples at 00:14 (5(a) and 5(b)), 12:29

$6 \quad(5(\mathrm{c})$ and 5(d)) and 01:14 (5(e) and 5(f)). In the last case there is no data with the before-

7 calculation filter. In most of the scans, noise at the farthest ranges is removed when filtering

8 before calculation, as seen by comparing Fig. 5(a) and 5(b). However, there can be some

9 over-filtering with before-calculation filter, as seen by comparing Fig. 5(c) and 5(d). Some

10 valid data points have been removed alongside with noise and only data of several range bins

11 remains. In some extreme cases with clear sky conditions (e.g. Fig. 5(e) and 5(f)), the before-

12 calculation filter will remove all data. This is the case when aerosol concentrations are too

13 low to provide enough backscatter data. For an experienced researcher, it is not hard to

14 distinguish the noise, but that may not be the case for untrained users. Thus we would suggest

15 to apply the before-calculation filter for operational purpose because of its higher reliability,

16 but the after-calculation filter for research purpose, since more usable data points will be kept.

17 In the rest of this paper we use the filter after calculation (Combi-A) if not specified

18 otherwise.

(a)

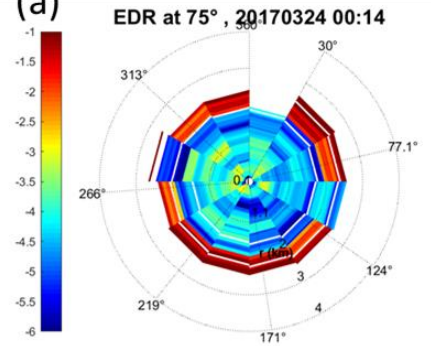

(c)

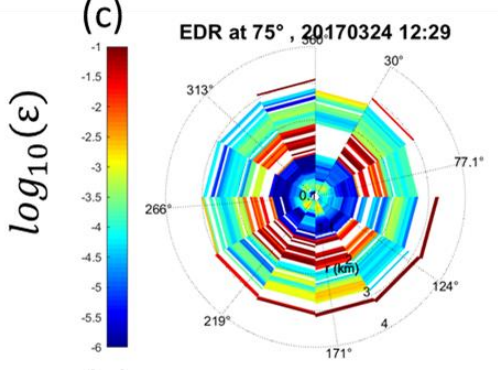

(e)

$(\mathrm{e})$
-1.5
-2
-2.5
-3
-3.5
-4
-4.5
-5
-5.5
-6
EDR at $75^{\circ}, 20170324$ 02:14

$$
30^{\circ}
$$

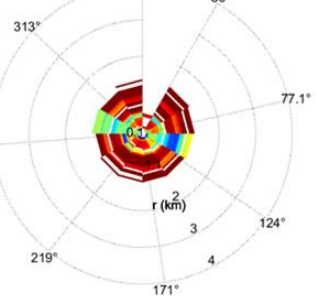

(b) EDR at $75^{\circ}, 20.17032400: 14$

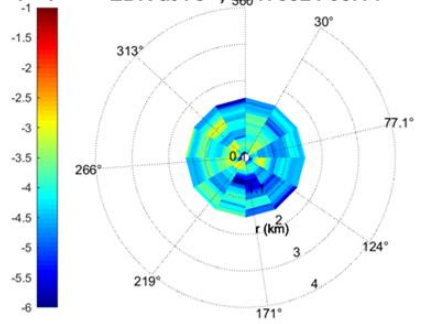

(d) EDR at $75^{\circ}, 2017032412: 29$

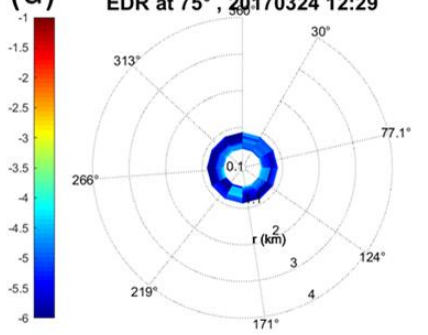

(f)

EDR at $75^{\circ}, 20170324$ 02:14

No Data 
Atmos. Meas. Tech. Discuss., https://doi.org/10.5194/amt-2019-3

Figure 5. Base 10 logarithm of EDR $\left[\mathrm{m}^{2} \mathrm{~s}^{-3}\right]$ retrieved by longitudinal approach at three times (top: 00:14, centre: 12:29 and bottom: 02:14) on 24 March 2017, with the aftercalculation filter $(a, c, e)$ and before-calculation filter $(b, d, f)$. There is no remaining data at 01:14 if we use the before-calculation filter.

\section{$6 \quad 3.2$ EDR estimation}

7 We have applied the EDR retrieval algorithm to data from the lidar at IMO. We choose two examples in this study: 24 March 2017 as a turbulent case and 31 March 2017 as a calm case. Figure 6 compares the derived EDR using different scan strategies (vertical to VAD), structure functions (azimuthal to longitudinal approach), elevation angles $\left(75^{\circ}\right.$ to $\left.15^{\circ}\right)$, and in different weather conditions (turbulent and calm). The received lidar backscattered signal is directly related to the size and amount of particles in the atmosphere. Higher concentration or larger particles means higher received signal, or higher CNR values (see Fig. 4). From the Fig. 4 and previous research (O'Connor et al., 2010), we know most of the signal come from the well mixed boundary layer which height can vary from tens of meters to a few kilometers (Stull, 1988). Above the boundary layer, the CNR is usually lower and the signal is dominated by noise. In general, one would expect the boundary layer to be thicker when the conditions are turbulent than in calm conditions, due to stronger vertical mixing process. This explains why there is a clear difference in detection height between the more turbulent day (Fig. 6, left panel) when the detection height is about $3.5 \mathrm{~km}$ altitude and the calm day (Fig. 6, right panel) where it is only about $1.5 \mathrm{~km}$. Normally, the lidar can capture the efficient backscatter signal up to the top of boundary layer, but sometimes we can also see the strong signal above it, like the ice cloud around 12 UTC on 24 March. 
Atmos. Meas. Tech. Discuss., https://doi.org/10.5194/amt-2019-3

Manuscript under review for journal Atmos. Meas. Tech.

Discussion started: 9 January 2019

(c) Author(s) 2019. CC BY 4.0 License.
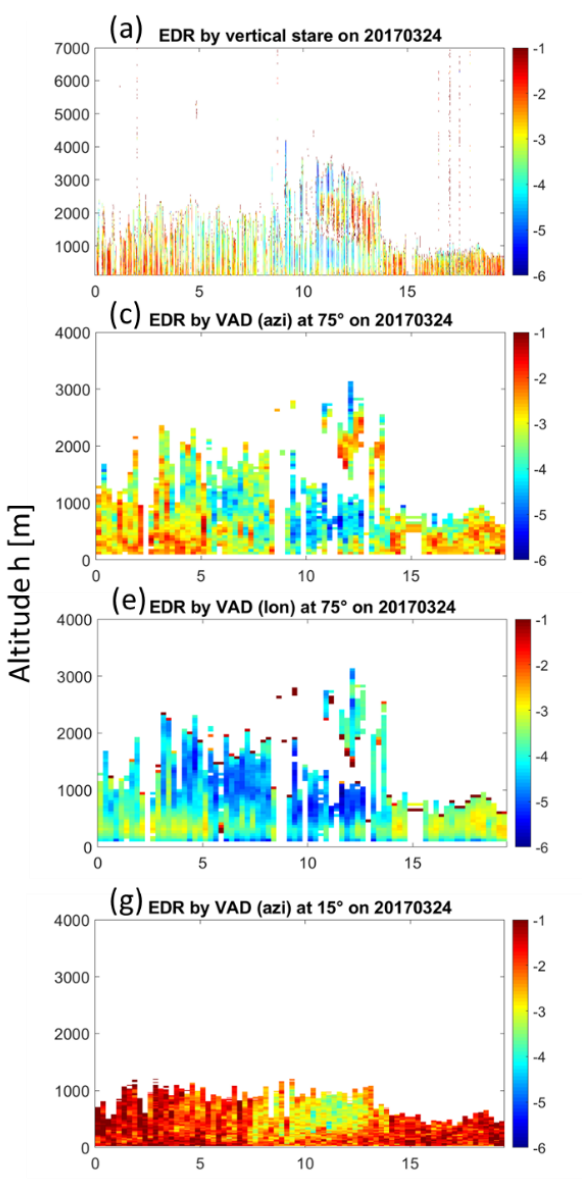
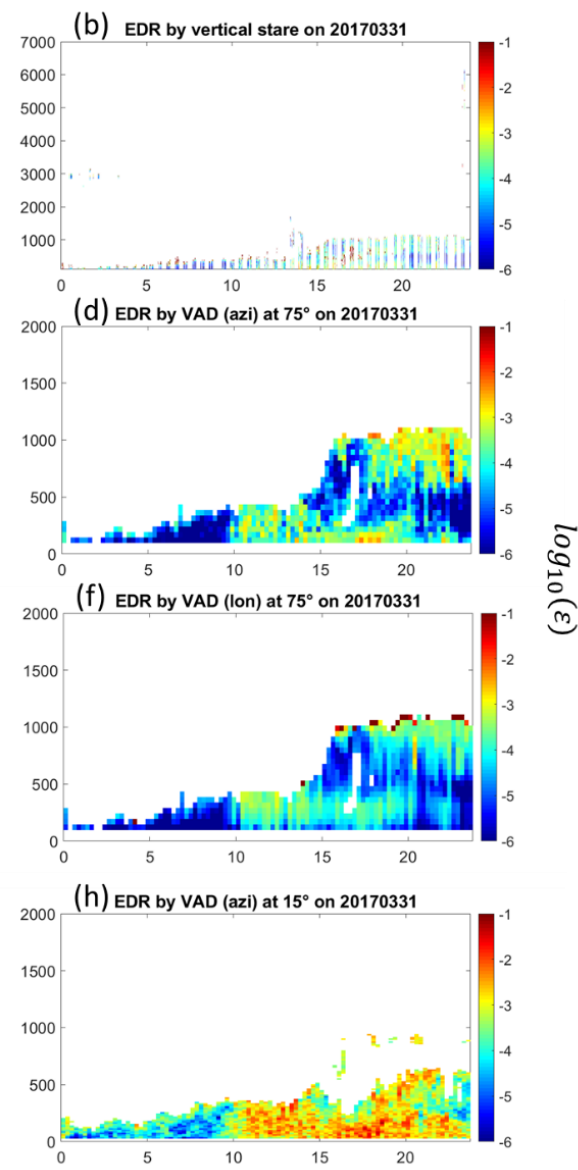

1

Figure 6. Comparison of base 10 logarithms of eddy dissipation rate (EDR $\left.\left[\mathrm{m}^{2} \mathrm{~s}^{-3}\right]\right)$ on 24 March 2017 (left panels) and 31 March 2017 (right panels). EDR is derived from the vertical stare ( $a$ and $b$ ), VAD scans using the azimuthal approach (azi) with $75^{\circ}$ elevation angle (c and $d$ ), longitudinal approach (lon) with $75^{\circ}$ angle ( $e$ and $f$ ), and azimuthal approach with $15^{\circ}$ elevation angle $(g$ and $h)$. Note the different vertical axis.

As seen in Fig. 6, the EDR retrievals using the structure function on VAD scans are quantitatively similar to the EDR retrievals from the vertical stare applying the method of (O'Connor et al., 2010). In the early morning and late night of $24 \mathrm{March}$, there are high values of EDR in four figures (Fig. 6, left panel), indicating turbulent conditions. On the calm day, 31 March, turbulence is detected after 10 UTC in all four figures (Fig. 6, right panel), and we can also see that in the afternoon, from 15 UTC, the top and bottom of the boundary layer was more turbulent than the middle of the boundary layer. In Fig. 6(e), an EDR maximum layer can be identified around $250 \mathrm{~m}$, and similar results can be found in some other days' longitudinal data (not shown). This does not mean that there is a constant layer at that altitude, because it may be found from the data with $15^{\circ}$ elevation angle, but at lower altitude. This cannot be found in azimuthal approach, so we tend to exclude the reason from 
1 lidar itself. The likely reason is the better data availability at lower altitude which may result

2 in the moving average algorithm introducing this pseudo-layer in some certain weather

3 situation, which is still unknown to us. The comparison between azimuthal (Fig. 6(c) and 6(d)) and longitudinal (Fig. 6(e) and 6(f)) approaches shows that they yield similar turbulence patterns, both in the turbulent and in the calm case. However, the longitudinal approach, besides the unfiltered noise signal at the edge of different columns, which we have discussed in Sect. 3.1, yields lower absolute EDR values. In other words, some severe turbulent events have been underestimated. This is more obvious in the turbulent case (24 March). This results from our time series analysis: we apply one more averaging calculation on the longitudinal approach than on the azimuthal approach, averaging the EDR at each range gate, to plot the altitude to time figure. In this way, some turbulence will be averaged out, or smoothed. As turbulence is a sudden change of airflow on a small temporal and spatial scale, more averaging calculations means less turbulence is detected. In this regard, the azimuthal approach performs better on EDR retrieval. As mentioned above, we use the VAD scans at two elevation angles, $15^{\circ}$ and $75^{\circ}$. Due to the basic geometry, higher elevation angle means higher upper and lower detection limits. Thus, a low elevation scan could provide more information at lower altitude. The scans at different elevation angles do not execute simultaneously, and we do not expect a perfect match of EDR. However, the results of the $15^{\circ}$ elevation angle (Fig. 6(g) and (h)) shows significant higher EDR value than at $75^{\circ}$. One possible explanation is that the lower elevation angle results in higher vertical resolution (25.9 $\mathrm{m}$ to $96.6 \mathrm{~m}$ at $75^{\circ}$ ), which means better ability to distinguish small scale turbulence. However, the heterogeneity of the atmosphere should also be kept in mind. With a low elevation angle, further range gates also mean a larger distance from the zenith position, resulting in lower representativeness and higher uncertainty. For example, at $75^{\circ}$ elevation angle, the straight line distance between two adjacent data points at $1000 \mathrm{~m}$ range gate would be $517 \mathrm{~m}$, while at $15^{\circ}$ elevation angle it is $1931 \mathrm{~m}$. Besides, it is also possible that more turbulence happens near surface due to friction. We recommend combining both scan angles operationally: the low elevation scan gives high resolution measurement at lower altitude, and the high elevation scan provides information with lower uncertainty at higher altitude.

Although the azimuthal approach performs better on the time series analysis, the longitudinal approach has its own advantage: it can retrieve EDR values along the beam, which allows us to examine where the turbulence occurs on a horizontal scale. Currently, we have two VAD scans at different elevation angles every 15 minutes. This enables us to detect in which direction and at which distance from the lidar turbulence is occurring. Figure 7 shows two examples from 24 March 2017: one is at 08:00 UTC when the atmosphere was relatively calm, as seen in Fig. 6, and another is at 16:14 UTC when the conditions were more turbulent. Ignoring the hot-spots at the edges, which are noise as we have discussed, we can see where, in horizontal space, turbulence is detected. In the morning, the turbulence mostly occurred at a lower level and close to the lidar. This can be seen at the $15^{\circ}$ angle but not $75^{\circ}$, because the first range gate is at $100 \mathrm{~m}$, corresponding to $96.6 \mathrm{~m}$ altitude at $75^{\circ}$ but only $25.9 \mathrm{~m}$ altitude at $15^{\circ}$ angle. In this case, the turbulence is occurring below $96.6 \mathrm{~m}$ and the VAD scan at $75^{\circ}$ cannot detect it. In the afternoon, more turbulence is detected (higher EDR values), and this agrees well with Fig. 6. 
Atmos. Meas. Tech. Discuss., https://doi.org/10.5194/amt-2019-3

Manuscript under review for journal Atmos. Meas. Tech.

Discussion started: 9 January 2019

(c) Author(s) 2019. CC BY 4.0 License.
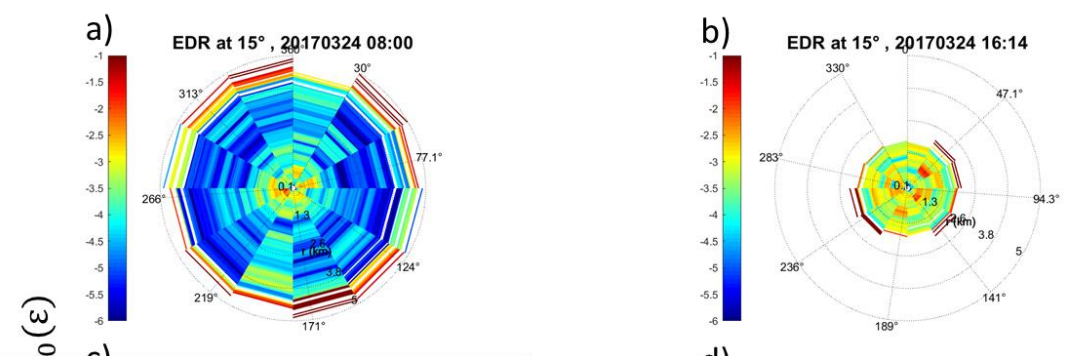

C) EDR at $75^{\circ}, 30.17032408: 00$
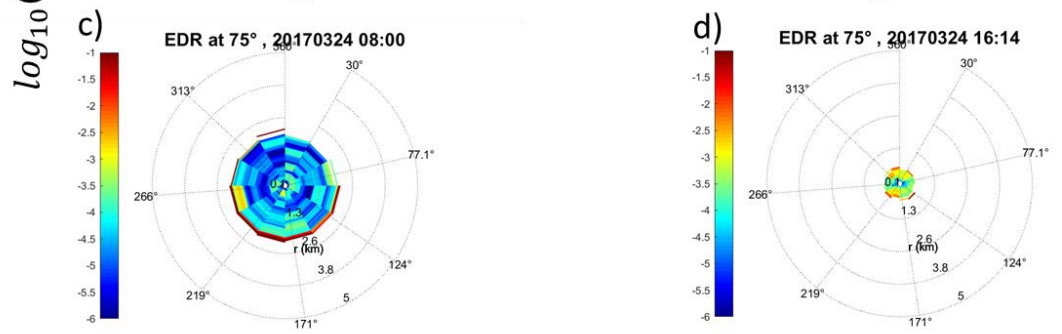

Figure 7. Beam-circular EDR $\left[\mathrm{m}^{2} \mathrm{~s}^{-3}\right]$ maps for two cases at 08:00 UTC (left) and 16:14 UTC (right) 24 March 2017. The data is from the VAD scan, at elevation angle $75^{\circ}$ (top) and $15^{\circ}$ (bottom), using the longitudinal approach. The radial direction indicates the distance from the lidar.

The azimuthal interval of current scanning is $30^{\circ}$, thus the distance between two data point could be larger than the scale of turbulence, which means the assumption of homogeneous atmosphere is less valid as we discussed above and the turbulence with small scale might be ignored. Potentially the azimuthal interval could be decreased but further research is needed on the effect of that on the EDR and the associated uncertainties. Further future considerations would also be to set up scans along airport runways. This has been done at some airports, such as Hong Kong airport (Hon and Chan, 2014). The results from our study will be valuable to air traffic controllers in Iceland, where weather and atmosphere conditions are distinctly different from Hong Kong. We have applied the algorithm to the other lidar system at Keflavik International airport, and the results are also online and accessible to the air traffic controllers in Iceland.

\section{Conclusion}

The current work suggests that it is possible to apply VAD scans and a structure function to derive an estimate of the EDR. The results are comparable to more conventional EDR retrievals using vertical stares. The algorithm works in different weather conditions. Iceland is in the subpolar region, and the data quality is not as good as it is in some other regions due to a lack of scatters, thus data quality control is especially important. Aerosol concentration in the atmosphere at high latitudes is often lower than at mid and low latitudes, which results in a weaker backscattered signal and the noise may be misinterpreted as severe turbulence. Finding a reliable algorithm to filter noise is thus important. Simply filtering data by the carrier-to-noise ratio is not reliable, since the signal strength can vary considerably from day to day, profile to profile. Besides, CNR values change with range, which makes it difficult to find a universal threshold. Applying a filter before or after the EDR calculation also makes a difference: with the same threshold, before-calculation filter remove most of the noise and some valid data, whereas after-calculation filter does not remove all of the noise. It is 
Atmos. Meas. Tech. Discuss., https://doi.org/10.5194/amt-2019-3

Manuscript under review for journal Atmos. Meas. Tech.

Discussion started: 9 January 2019

(c) Author(s) 2019. CC BY 4.0 License.

1 important to find a balance where as much of the noise as possible is removed while

2 simultaneously as many valid data points are kept. In the current phase, we would suggest

3 using the after-calculation filter for research purpose as it will keep more data points, and

4 using the before-calculation filter for operational purposes as it removes most of the noise.

5 We also tested two approaches to calculate the structure function from the VAD scan, and

6 they perform differently: the azimuthal approach performs better (in comparison to the

7 vertical stare) in time series analysis, and indicates when and at what altitude the turbulence

8 occurs, while the longitudinal approach is more suitable to show location of the turbulence

9 relative to the lidar on a horizontal scale. The EDR values vary with different VAD elevation

angle, thus a combination of both angles is recommended. Uncertainties are also introduced in a more theoretical way. To apply the Kolmogorov theory, we have to assume the atmosphere is homogeneous and isotropic, but as we have described, the VAD scan is cone-shaped, which means the assumption is only valid at lower range gates and at larger elevation angles. To apply this method in an operational way, we would suggest combining the VAD scan with two elevation angles: the lower angle scan can fill the gap between the surface and the first range gate of the higher angle scan, while the higher angle scan provides reliable information at higher altitude.

In general, the method of retrieving EDR from lidar data to estimate the turbulence intensity is possible and it can be applied to the air traffic control system in Iceland. Furthermore, at present there is ongoing work to make this algorithm operational and to find a solid threshold of different EDR value categories in practical use.

\section{Reference}

Chan, P. W.: Atmospheric turbulence in complex terrain: Verifying numerical model results with observations by remote-sensing instruments, Meteorol. Atmospheric Phys., 103(1-4), 145-157, doi:10.1007/s00703-008-0342-3, 2009.

Chan, P. W.: LIDAR-based turbulence intensity calculation using glide-path scans of the Doppler Llght Detection And Ranging (LIDAR) systems at the Hong Kong International Airport and comparison with flight data and a turbulence alerting system, Meteorol. Z., 19(6), 549-563, doi:10.1127/09412948/2010/0471, 2010.

Cohn, S. A.: Radar Measurements of Turbulent Eddy Dissipation Rate in the Troposphere: A Comparison of Techniques, J. Atmospheric Ocean. Technol., 12(1), 85-95, doi:10.1175/15200426(1995)012<0085:RMOTED>2.0.CO;2, 1994.

Frehlich, R.: Errors for Space-Based Doppler Lidar Wind Measurements: Definition, Performance, and Verification, J. Atmospheric Ocean. Technol., 18(11), 1749-1772, doi:10.1175/15200426(2001)018<1749:EFSBDL>2.0.CO;2, 2001.

Frehlich, R. and Cornman, L.: Estimating Spatial Velocity Statistics with Coherent Doppler Lidar, J. Atmospheric Ocean. Technol., 19(3), 355-366, doi:10.1175/1520-0426-19.3.355, 2002. doi:10.1175/JAM2368.1, 2006. techniques: A review, Radio Sci., 20(6), 1403-1422, doi:10.1029/RS020i006p01403, 1985. 
Atmos. Meas. Tech. Discuss., https://doi.org/10.5194/amt-2019-3

Manuscript under review for journal Atmos. Meas. Tech.

Discussion started: 9 January 2019

(c) Author(s) 2019. CC BY 4.0 License.

1 Hon, K. K. and Chan, P. W.: Application of LIDAR-derived eddy dissipation rate profiles in low-level

2 wind shear and turbulence alerts at Hong Kong International Airport, Meteorol. Appl., 21(1), 74-85,

3 doi:10.1002/met.1430, 2014.

4 ICAO: ICAO Annual Safety Report 2018, [online] Available from:

5 https://www.icao.int/safety/Documents/ICAO_SR_2018_30082018.pdf, Montreal, Canada, 2018.

6 Leosphere, Inc: WINDCUBE 100s-200s User Manual, Orsay, France, 2013.

7 Leung, M. Y. T., Zhou, W., Shun, C.-M. and Chan, P.-W.: Large-scale Circulation Control of the

8 Occurrence of Low-level Turbulence at Hong Kong International Airport, Adv. Atmospheric Sci., 35(4),

9 435-444, doi:10.1007/s00376-017-7118-y, 2018.

10 Manninen, A. J., O'Connor, E. J., Vakkari, V. and Petäjä, T.: A generalised background correction 11 algorithm for a Halo Doppler lidar and its application to data from Finland, Atmospheric Meas. Tech., 12 9(2), 817-827, doi:10.5194/amt-9-817-2016, 2016.

13 Manninen, A. J., Marke, T., Tuononen, M. and O'Connor, E. J.: Atmospheric Boundary Layer 14 Classification With Doppler Lidar, J. Geophys. Res. Atmospheres, 123(15), 8172-8189,

15 doi:10.1029/2017JD028169, 2018.

16 Misaka, T., Ogasawara, T., Obayashi, S., Yamada, I. and Okuno, Y.: Assimilation Experiment of Lidar 17 Measurements for Wake Turbulence, J. Fluid Sci. Technol., 3(4), 512-518, doi:10.1299/jfst.3.512, 182008.

19 O'Connor, E. J., Illingworth, A. J., Brooks, I. M., Westbrook, C. D., Hogan, R. J., Davies, F. and 20 Brooks, B. J.: A Method for Estimating the Turbulent Kinetic Energy Dissipation Rate from a Vertically 21 Pointing Doppler Lidar, and Independent Evaluation from Balloon-Borne In Situ Measurements, J.

22 Atmospheric Ocean. Technol., 27(10), 1652-1664, doi:10.1175/2010JTECHA1455.1, 2010.

Ólafsson, H. and Ágústsson, H.: The Freysnes downslope windstorm, Meteorol. Z., 16(1), 123-130, doi:10.1127/0941-2948/2007/0180, 2007.

Oude Nijhuis, A. C. P., Unal, C. M. H., Krasnov, O. A., Russchenberg, H. W. J. and Yarovoy, A.: Velocity-based EDR retrieval techniques applied to Doppler radar measurements from rain: Two case studies(under review), 2018.

Ramanathan, V., Crutzen, P. J., Kiehl, J. T. and Rosenfeld, D.: Aerosols, Climate, and the Hydrological Cycle, Science, 294(5549), 2119-2124, doi:10.1126/science.1064034, 2001.

30 Sharman, R.: Nature of Aviation Turbulence, in: Aviation Turbulence, edited by: Sharman, R. and

31 Lane, T., Springer International Publishing, Cham, Switzerland, 3-30, 2016.

Sinclair, P. C. and Kuhn, P. M.: Aircraft Low Altitude Wind Shear Detection and Warning System, J.

33 Appl. Meteorol., 30(1), 3-16, doi:10.1175/1520-0450(1991)030<0003:ALAWSD>2.0.CO;2, 1991.

34 Stull, R. B.: An Introduction to Boundary Layer Meteorology, Springer Science \& Business Media., 35 Doetinchem, Netherlands, 1988.

36 Thobois, L. P., Krishnamurthy, R., Loaec, S., Cariou, J. P., Dolfi-Bouteyre, A. and Valla, M.: Wind and 37 EDR Measurements with Scanning Doppler LIDARs for Preparing Future Weather Dependent 38 Separation Concepts (Invited), in 7th AIAA Atmospheric and Space Environments Conference,

39 American Institute of Aeronautics and Astronautics, Dallas, TX., 2015.

40 Tuononen, M., O'Connor, E. J., Sinclair, V. A. and Vakkari, V.: Low-Level Jets over Utö, Finland,

41 Based on Doppler Lidar Observations, J. Appl. Meteorol. Climatol., 56(9), 2577-2594,

42 doi:10.1175/JAMC-D-16-0411.1, 2017. 
Atmos. Meas. Tech. Discuss., https://doi.org/10.5194/amt-2019-3

Manuscript under review for journal Atmos. Meas. Tech.

Discussion started: 9 January 2019

(c) Author(s) 2019. CC BY 4.0 License.

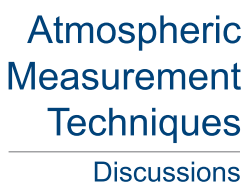

(c) (i)

1 Wächter, M. and Rettenmeier, A. K.: Characterization of short time fluctuations in atmospheric wind

2 speeds by LIDAR measurements, Meteorol. Z., 277-280, doi:10.1127/0941-2948/2009/0376, 2009. 